\title{
Millimeter Wave Substrate Integrated Waveguide Antennas: Design and Fabrication Analysis
}

\author{
M. Henry, Member, IEEE, C. E. Free, Member, IEEE, B. S. Izqueirdo, J. Batchelor, Member, IEEE, and \\ P. Young, Member, IEEE
}

\begin{abstract}
The paper presents a new concept in antenna design, whereby a photo-imageable thick-film process is used to integrate a waveguide antenna within a multilayer structure. This has yielded a very compact, high performance antenna working at high millimeter-wave (mm-wave) frequencies, with a high degree of repeatability and reliability in antenna construction. Theoretical and experimental results for $70 \mathrm{GHz}$ mm-wave integrated antennas, fabricated using the new technique, are presented. The antennas were formed from miniature slotted waveguide arrays using up to 18 layers of photo-imageable material. To enhance the electrical performance a novel folded waveguide array was also investigated. The fabrication process is analyzed in detail and the critical issues involved in the fabrication cycle are discussed. The losses in the substrate integrated waveguide have been calculated. The performance of the new integrated antenna is compared to conventional metallic, air-filled waveguide antennas, and also to conventional microstrip antenna arrays operating at the same frequencies.
\end{abstract}

Index Terms-Millimeter wave antenna arrays, substrate integrated waveguides (SIW), photo-imageable fabrication, slotted waveguide antenna arrays.

\section{INTRODUCTION}

$\mathbf{S}$ UBSTRATE integrated circuits (SICs) are a new concept for high-frequency electronics, which yields high performance from very compact planar circuits [1]. The basic idea behind the technique is that of integrating nonplanar 3-D structures within a multilayer circuit. However, existing integration techniques using precision machining cannot economically achieve the required precision for millimeter-wave (mm-wave) components, particularly for mass production. In the last few years a number of papers based on substrate integrated circuits and waveguides (SICs, SIWs) on planar microstrip substrates have appeared in the literature, but only for frequencies up

Manuscript received September 08, 2007; revised August 04, 2008. Current version published February 13, 2009. This work was supported in part by the EPSRC Grants for University of Surrey under Grant GR/S62369/01 and in part by the University of Kent under Grant GR/S62352/01. This work was recommended for publication by Associate Editor S. Dvorak upon evaluation of the reviewers comments.

M. Henry was with Advanced Technology Institute, University of Surrey, GU2 7XH Guildford, U.K. She is now with Rutherford Appleton Laboratory, Space Science and Technology Department, OX11 0QX Oxfordsire, U.K. (e-mail: manju.henry@stfc.ac.uk).

C. E. Free is with the Advanced Technology Institute, University of Surrey, GU2 7XH Guildford, Surrey, U.K. (e-mail: c.free@ surrey.ac.uk).

B. S. Izquierdo, J. C. Batchelor, and P. Young are with the Department of Electronics, University of Kent, CT2 7NT Kent, U.K.

Color versions of one or more of the figures in this paper are available at http://ieeexplore.ieee.org

Digital Object Identifier 10.1109/TADVP.2008.2011284 to X-band. Most of the integrated waveguides that have been reported used VIA fenced sidewalls, realized using relatively elementary fabrication techniques. With these techniques the diameter and spacing of the individual VIAs will affect the loss and bandwidth of the waveguide [2], [3]. Such integrated structures cannot be regarded as homogeneous waveguide, but will be similar in performance to an artificial periodic waveguide.

However, there have been a number of successful attempts to form substrate integrated waveguides using micro-machining techniques. McGrath et al. [4] formed an air-filled waveguide channel in silicon, and reported measured losses of around $0.02 \mathrm{~dB} / \mathrm{mm}$ at $100 \mathrm{GHz}$. In [5], Digby et al., used a different micro-machining process to form a substrate integrated $100 \mathrm{GHz}$ air-filled waveguide. Their measured data, around $0.05 \mathrm{~dB} / \mathrm{mm}$ at $100 \mathrm{GHz}$ was slightly higher than that of McGrath, but it was suggested by the authors that the high attenuation might have been due to some of the waveguide walls being only one skin depth thick. A further variation of the air-filled SIW structure was reported by Collins et al. [6], who used a micro-machining approach to form the waveguide trough on one substrate, and this was combined with a second substrate using a "snap-together- technique," to form the final enclosed waveguide. This was a somewhat simpler fabrication approach than that used by McGrath, and by Digby, and this was reflected in the higher measured attenuation of around $0.2 \mathrm{~dB} / \mathrm{mm}$ at $100 \mathrm{GHz}$. The key differences between the present work, and that of authors using micro-machining, are that a very low cost technique was used to form dielectric-filled waveguides, leading to structures that were inherently robust and cheap.

The primary objective of the present paper is to provide an in-depth analytical investigation of the fabrication techniques that could be employed to integrate efficiently novel 3-D waveguide structures within ceramic circuit modules. However, the necessary inclusion of dielectric within the waveguide restricts the use of these circuits above $100 \mathrm{GHz}$, with this frequency limit being mainly decided by the loss tangent of the integrated substrate material.

This paper describes the techniques for integrating mm-wave antennas within ceramic modules using a relatively new process, namely photo-imageable thick-film [7], [8]. Since this type of process enables the circuit structure to be built up layer-by-layer, it is ideal for forming 3-D structures. The work described in the paper demonstrates the viability and potential of photo-imageable fabrication technology through the measured, practical performance of novel $\mathrm{mm}$-wave integrated antennas arrays working around $70 \mathrm{GHz}$. 


\section{FABRICATION METHODOLOGY}

Photo-imageable thick-film conductors and dielectric contain a photo vehicle with the pastes. This enables layers of conductor or dielectric to be printed and then directly imaged using UV radiation. The system enables fine lines and gaps to be fabricated with dimensions down to $10 \mu \mathrm{m}$. Moreover, because structures can be built up layer-by-layer, it is easy to provide interconnections between planar and nonplanar circuits within a single ceramic circuit. This scheme can be used to design low-cost, high-performance passive circuits such as resonators, filters, power dividers, etc. [9], [10]. A further advantage is that the technology is compatible with many fabrication processes such as thin film, HTCC, and LTCC. A particular advantage of photo-imageable materials for the work being reported here is that the sidewalls of the integrated waveguides can be made from continuous metal, rather than using a VIA fence. The process of making such a sidewall is simply to develop channels in the dielectric layer, and then to subsequently fill them with metal.

\section{A. Photo-Imageable Fabrication}

The process mainly consists of four main steps as shown in the Fig. 1.

Step 1) The thick film paste is screen printed on alumina substrate, leveled at room temperature and dried at $80{ }^{\circ} \mathrm{C}$ for $45 \mathrm{~min}$.

Step 2) The printed paste is exposed to UV through photo patterned chrome masks and in the exposed region the paste polymerizes and hardens.

Step 3) The unexposed material is removed by spraying the circuit with developer, and finally dried with an air spray.

Step 4) The circuit is fired at $850{ }^{\circ} \mathrm{C}$ for $60 \mathrm{~min}$ to burn off the binders in the paste and leave the final pattern of conductor or dielectric.

Unlike the conventional metal etching process the photo-imageable fabrication does not require the intermediate photo-resist spinning and developing as the photo-vehicle required for UV exposure and hardening is contained in the material itself. The advantage of using this fabrication is the ability of the process to achieve the fine geometries demanded by mm-wave circuits.

\section{B. Waveguide Integration}

The 3-D waveguide structures were built up, layer-by-layer, using the photo-imageable thick-film process. The layers were printed onto an alumina base to give rigidity to the final structure. A layer of silver conductor (Fodel 6778) paste was first printed onto the alumina to form the bottom broad wall of the waveguide [Fig. 2(a)]. Next, a layer of dielectric (Fodel QM44F) is screen printed, photo-imaged and fired to form vertical trenches. Conductor paste is then screen printed and photo-imaged to fill the trenches, so forming the sidewalls of the waveguide [Fig. 2(b)]. These last two steps were repeated a number of times to build up the required height of the waveguide. Finally, the top layer of conductor is printed, and radiating slots are photo-imaged and fired to form the top wall of the waveguide [Fig. 2(c)]. The schematic view of the cross

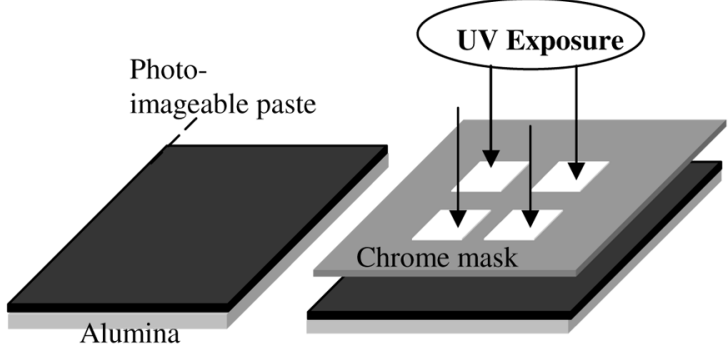

(a)

(b)

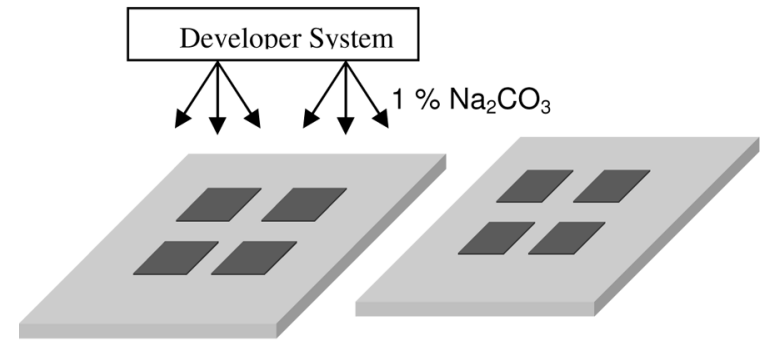

(c)

(d)

Fig. 1. Steps in a photo-imageable process (a) printing (b) exposure (c) developing (d) firing.

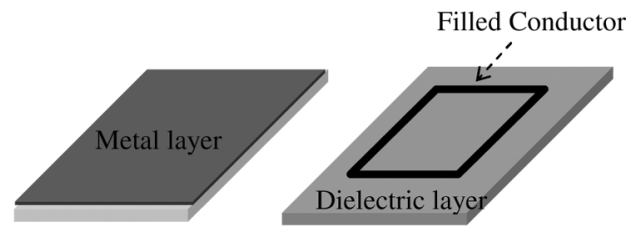

(a)

(b)

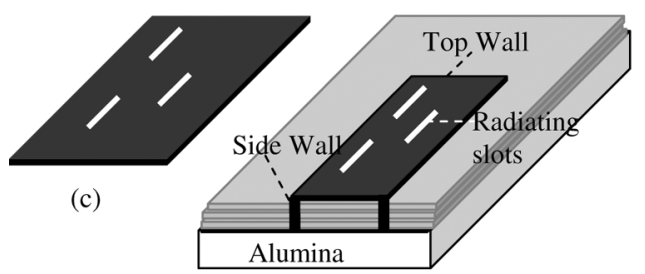

(d)

Fig. 2. Steps in a waveguide integration process, printing (a) bottom wall (b) side walls (c) top wall and radiating slots. (d) Cross-sectional view of the integrated waveguide on alumina substrate.

section of the integrated waveguide is shown in Fig. 2(d). It was found to be necessary to have the registration of intermediate layers accurate to within $\pm 1 \mu \mathrm{m}$, which required a sophisticated mask aligner for exposing each layer. The uniformity of the sidewalls is a critical factor in the integration process, as nonuniform sidewalls will lead to significant loss in the structure.

\section{Fabrication Analysis}

1) Fabrication Quality: Clearly, with antennas operating at very high frequencies, and consequently very small wavelengths, the quality and accuracy of the fabrication process is a key issue. In our case it was important that the radiating slots were being formed with precise dimensions and high quality edges. To demonstrate the quality of the fabrication process, an enlarged version of one of the radiating slots is shown in Fig. 3(a). To further indicate the quality achievable with the 


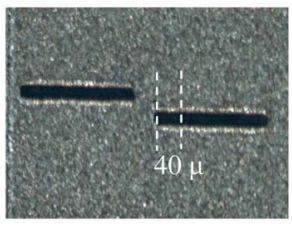

(a)

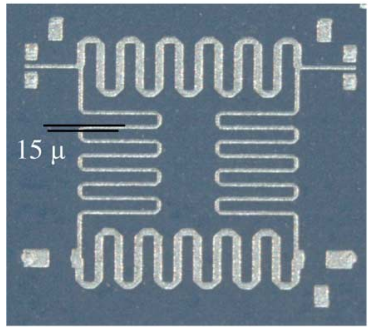

(c)

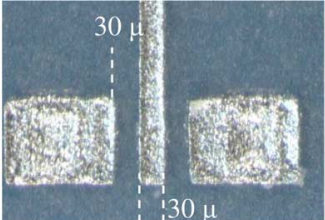

(b)

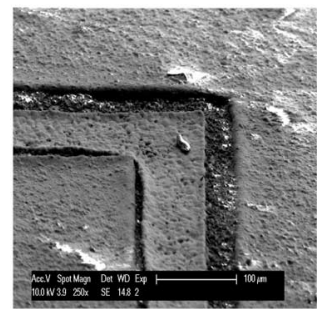

(d)

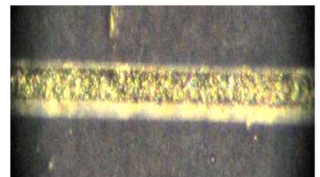

(a)

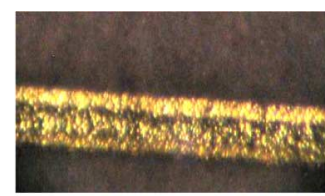

(b)
Fig. 4. Photographs of conductor surface to show (a) shrinkage after firing, (b) and after optimizing the fabrication process.

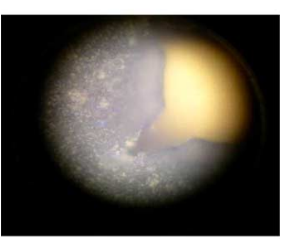

(a)

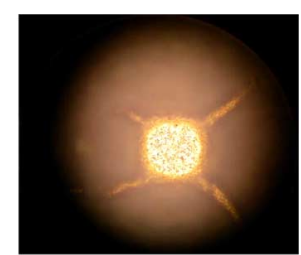

(b)
Fig. 3. (a)-(c) Photographs showing the quality and capability of the fabrication process under careful control of the processing parameters. (d) SEM picture showing the shrunk conductor strip inside the trench after firing.

TABLE I

RATE OF SHRINKAGE ON CONDUCTORS, DIELECTRICS AND CIRCUITS OF DIFFERENT GEOMETRIES

\begin{tabular}{|l|l|l|l|}
\hline \multicolumn{1}{|c|}{ Type } & $\begin{array}{c}\text { Original } \\
\text { Dimension } \\
(\mathrm{mm})\end{array}$ & $\begin{array}{c}\text { Fabricated } \\
\text { Dimension } \\
(\mathrm{mm})\end{array}$ & $\begin{array}{c}\text { Percentage } \\
\text { of Shrinkage }\end{array}$ \\
\hline $\begin{array}{l}\text { Length of } \\
\text { the slot }\end{array}$ & 0.732 & 0.72 & $1.6 \%$ \\
\hline $\begin{array}{l}\text { Width of the } \\
\text { slot }\end{array}$ & 0.04 & 0.05 & $25 \%$ \\
\hline $\begin{array}{l}\text { Waveguide } \\
\text { width }\end{array}$ & 1.294 & 1.266 & $2.16 \%$ \\
\hline $\begin{array}{l}\text { Microstrip } \\
\text { line width }\end{array}$ & 0.06 & 0.055 & $8.33 \%$ \\
\hline
\end{tabular}

photo-imageable process, $50-\Omega$ GSG coplanar probe pads with $30 \mu \mathrm{m}$ spacing between the signal line and ground pads is shown in Fig. 3(b), and a fabricated miniature branch line coupler in Fig. 3(c).

\section{2) Fabrication Issues:}

a) Shrinkage: The main problem encountered with the photo-imageable fabrication process was shrinkage in the conductors and dielectrics during firing. In particular, the amount of shrinkage was different for the conductors and dielectrics. Also, it was found that the degree of shrinkage varied with the area of conductor or dielectric being fired. The difference in the rates of shrinkage for conductors, dielectrics, and circuits of different geometries and areas are given in Table I. The significance of the data in Table I is that it shows that it is not uniformly observed throughout the fabrication cycle and therefore cannot be taken into account at the design stage. The shrinkage was a serious issue when trying to fill VIAs and trenches. An SEM picture of a trench filled with conductor at an intermediate stage in the waveguide fabrication is shown in Fig. 3(d). After firing the inner conductor shrinks creating spaces on either side of the wall.

It was found that the only way to overcome fabrication issues related to shrinkage is to carefully control the process. The fabrication parameters (development and exposure times) need
Fig. 5. The dielectric layer of thickness $60 \mu \mathrm{m}$ printed and dried without intermediate firing steps showing cracks at the corners after firing; (a) track corner; (b) VIA corners.

to be refined for different layers, and for different circuit geometries. In the integration process described in this paper the shrinkage in VIAs and trenches was compensated in the $z$-direction by printing extra conductor layers. Correct compensation in the $x-y$ plane was achieved by increasing the exposure time and decreasing the development time. To illustrate the effectiveness of this technique Fig. 4(a) shows the trenches filled before compensation for shrinkage, and Fig. 4(b) shows the conductor-filled trenches after compensation.

In order to achieve the required degree of interlayer resolution, a Quintel Q7000 mask aligner was used. To achieve optimum resolution it was found that some care was needed in the choice of alignment marks to ensure they were compatible with the mask aligner being used.

b) Processing Time: In this study, 250 mesh stainless steel screens were used to print the dielectric, giving a postfiring thickness of around $15 \mu \mathrm{m}$. The conductor thickness, using 325 mesh screens for printing, was around $8 \mu \mathrm{m}$ after firing. The total inner height of the integrated waveguide shown in Fig. 2. was $60 \mu \mathrm{m}$. This was formed from four layers of dielectric. In all, eight layers of conductor were needed, including trench filling and compensating for shrinkage. Using this technique, the time required to finish a layer was one day, the most time consuming aspect being the firing and cooling in a single chamber furnace. So integrating a waveguide section of $60 \mu \mathrm{m}$ occupied around one and a half week. Hence, it was attractive to try and save processing time by printing and drying a number of layers and then co-firing in one step. Our experience was that circuits would develop cracks at the corners after firing. The results of an unsuccessful attempt to build a $60-\mu \mathrm{m}$-thick dielectric prior to firing are shown in Fig. 5, where significant cracking is evident.

\section{INTEGRATED ANTENNA DESIGNS}

This section discusses the design, simulation and theoretical analysis of two different antenna topologies operating around 


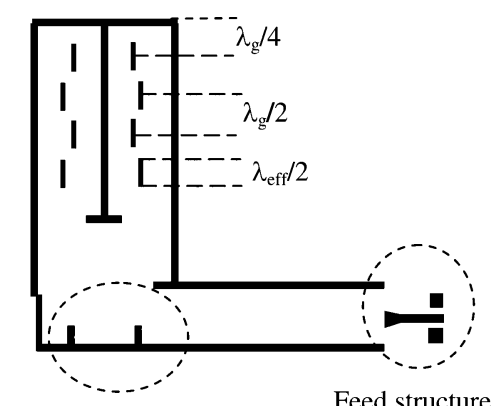

Side fed H-plane power divider

Fig. 6. Schematic showing the antenna structure.

$75 \mathrm{GHz}$ and integrated into a single ceramic structure. Two structures were considered:

1) A simple substrate integrated waveguide antenna consisting of a $2 \times 4$ array of slots.

2) A novel folded waveguide antenna array.

\section{A. Simple Integrated Waveguide Antenna Arrays}

1) Antenna Structure: Fig. 6 shows the structure of a simple integrated waveguide antenna, consisting of a $2 \times 4$ array of radiating slots. The feed consisted of a $50-\Omega$ microstrip line with a tapered transition to provide impedance matching between the microstrip and the integrated waveguide section [11]. The input power is split equally into two linear arrays each having four slots, using a conventional side-fed H-plane divider [12], where the separation between the two inductive walls can be adjusted for maximum coupling into both sections. This feeding technique introduces a phase difference of $180^{\circ}$ between the two linear arrays. Hence, the slots either side of the dividing wall array were positioned on opposite sides of the respective waveguides to give a further $180^{\circ}$ phase difference This ensured that all the eight slots of the antenna radiated in phase.

The end slots were positioned a distance of $\lambda_{g} / 4$ from the shorted ends of the waveguide, as shown in Fig. 6, with the remaining slots separated by $\lambda_{g} / 2$, so that all the slots would be exited by maxima in the standing wave patterns. Thus the slot positions ensured maximum radiation from the antenna.

The slot lengths were $\lambda_{\text {eff }} / 2$ to ensure good radiation, without causing end-to-end mutual coupling between adjacent slots. The physical lengths $\left(l_{s}\right)$ of the slots can be calculated from

$$
l_{s}=\frac{\lambda_{\mathrm{eff}}}{2}=\frac{\lambda_{0}}{\sqrt{2\left(\varepsilon_{r}+1\right)}}
$$

where $\lambda_{0}$ is the free space wavelength and $\varepsilon_{r}$ is the permittivity of the dielectric.

2) Antenna Dimensions: The dielectric waveguide antenna array with radiating slots was designed using conventional dielectric waveguide theory [13], [14]. The design was then simulated and optimised using 3-D electromagnetic simulation software HFSS to obtain maximum radiation. The optimized dimensions for a $2 \times 3$ slot array are shown in Fig. 7, where all dimensions are in millimeters. The simulation results are shown in Fig. 8 for a representative SIW antenna; it should be noted that the simulation was performed for at $76 \mathrm{GHz}$ using Hybridas HD1000 thick-film dielectric, whereas our SIW antennas were

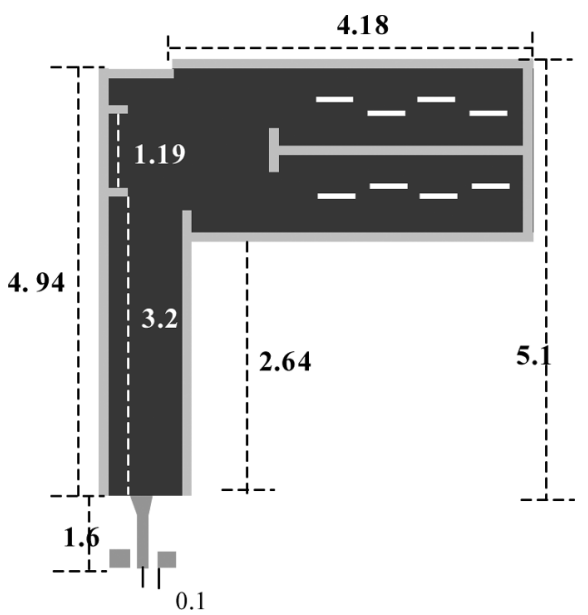

Fig. 7. Schematic showing integrated slotted waveguide antenna dimensions: all dimensions given here are in millimeters.

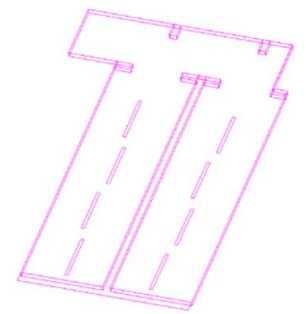

(a)

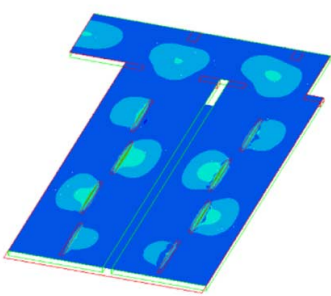

(b)

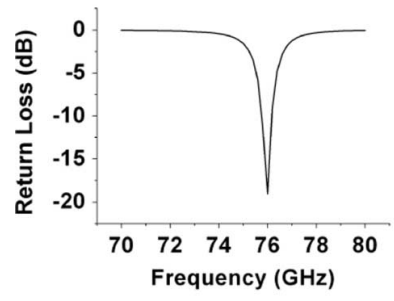

(c)

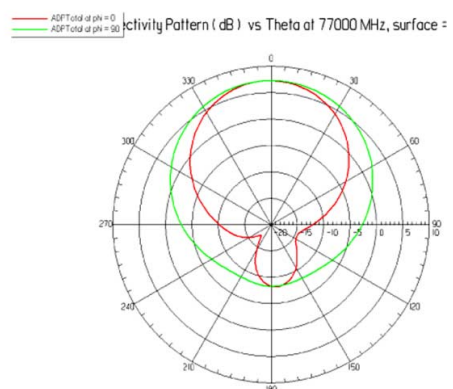

(d)
Fig. 8. (a) HFSS model, (b) field pattern, (c) return loss (d) radiation pattern at E-plane and H-plane, for the SIW antenna optimised for $76 \mathrm{GHz}$ and obtained from simulation.

integrated using a similar but slightly different dielectric namely Dupont QM 44 F due to the unavailability of the earlier paste in the market.

3) Experimental Results: The return loss and radiation pattern for the integrated waveguide $2 \times 3$ array are plotted in Fig. 9; the return loss shows a good match at the design frequency, and there is a well defined radiation pattern, with the cross-polar level more than $20 \mathrm{~dB}$ down on copolar level.

\section{B. Folded Waveguide Antenna Arrays}

The concept of an antenna array using a folded waveguide was proposed to extend the substrate integration strategy to lower frequencies [15]. The $\mathrm{TE}_{10}$ mode in a folded waveguide resembles that of a conventional rectangular waveguide. As a result of this folding, as shown in Fig. 10, the width (a) of the guide is reduced by $50 \%$, and the height of the guide is doubled (b). But, the height has got little effect on the propagation 


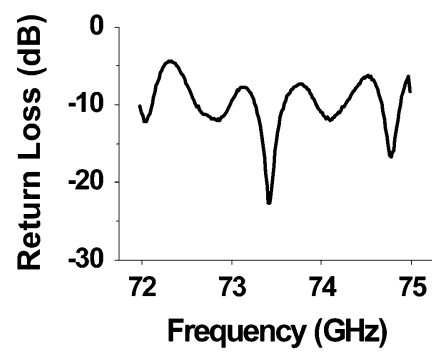

(a)

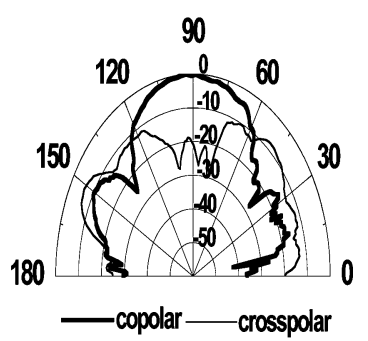

(b)
Fig. 9. Experimental results for a $2 \times 3$ antenna array (a) return loss (b) radiation pattern at $73.5 \mathrm{GHz}$.

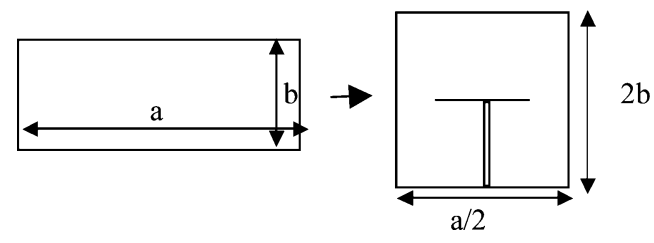

Fig. 10. Folded Waveguide antennas-Basic Concept.

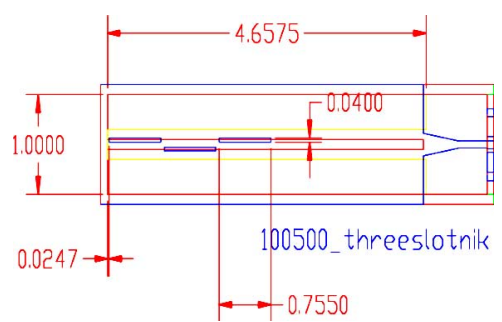

Fig. 11. Design dimensions of a four slot folded waveguide antenna, all dimensions are in millimeters.

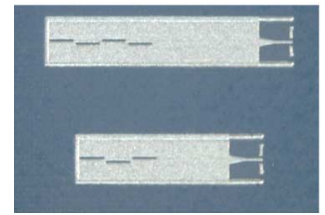

(a) (b)

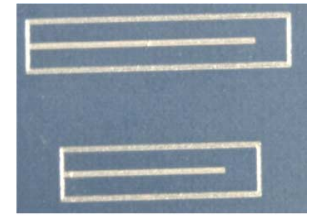

Fig. 12. Integrated folded waveguide antenna (a) top conductor layer, (b) intermediate conductor layer.

characteristic and can be set as small as required. So the overall effect is to reduce the substrate area occupied by the antenna.

1) Antenna Structure and Dimensions: The dimensions of a 74-GHz, 4-slot folded waveguide antenna were optimised using HFSS and the results are shown in Fig. 11.

The antenna was fabricated using the photoimageable process that has been described previously. The photographs in Fig. 12(a) and (b) show the top and the intermediate layers during the fabrication of a folded waveguide antenna. As well as showing the structure of the antenna, these photographs are a further indication of the quality of the photoimageable thick-film process. It can be seen from Fig. 13 that the measured return loss of the back-to-back transition is very good, greater

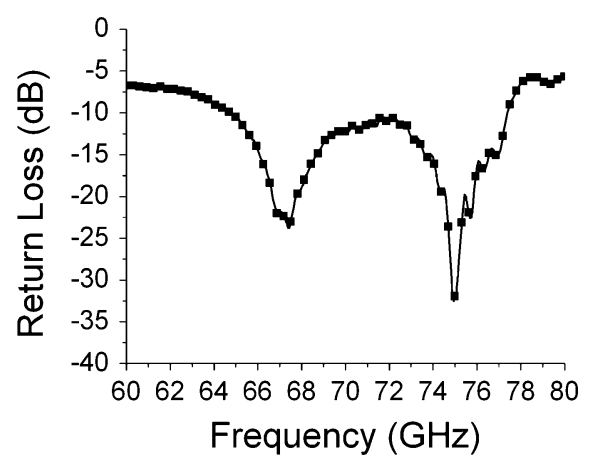

Fig. 13. Measured return loss of a back-to back folded waveguide transition.

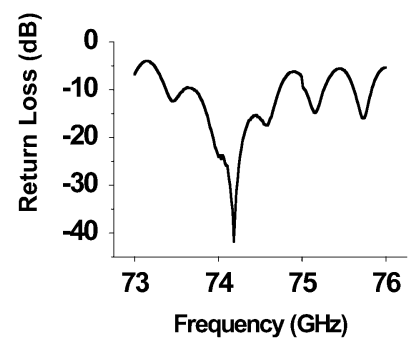

(a)

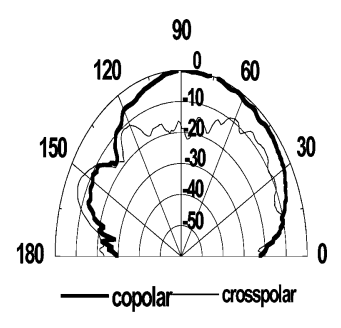

(b)
Fig. 14. Folded Waveguide Antenna (a) return loss (b) radiation pattern.

than $20 \mathrm{~dB}$, in the vicinity of the working frequency, showing that the transition as behaving as expected.

2) Experimental Results: The return loss and radiation pattern for a 4-slot folded waveguide antenna are shown in Fig. 14. The antenna shows good cross-polar level and a good match close to the resonant frequency.

\section{INTEGRATED WAVEGUIDE LOSS ANALYSIS}

Since the antenna were fabricated using integrated waveguides, it was important to gain some insight into the practical losses of the waveguide. To achieve this, waveguide lines of different lengths, but with the same cross sections, were fabricated and the line loss measured using a vector network analyzer (HP $8510 \mathrm{XF}$ ), which had previously been calibrated using an on-wafer calibration kit. The ends of the wave-guide sections were tapered to connect with the coplanar probing pads. Each tapered section had an axial length of $2 \mathrm{~mm}$. The return loss and insertion loss of integrated waveguides of length $1.9 \mathrm{~mm}$ and width $1.266 \mathrm{~mm}$ are plotted in Fig. 15.

The results show that the integrated waveguide structure, including the tapered sections, has relatively low insertion loss up to $100 \mathrm{GHz}$, with a value of $\sim 2 \mathrm{~dB}$ at the antenna design frequency $(74 \mathrm{GHz})$. The losses tend to increase with frequency due to increase in dielectric loss and conductor surface losses. The losses in the tapered feeds, and also the probe-circuit mismatch losses, were de-embedded by computing the difference in the insertion losses of two wave-guide structures of different lengths. After de-embedding, the magnitude of the loss in the SIW was calculated and the loss is plotted as a function of frequency in Fig. 16. Fig. 17 shows the wave number and guided 


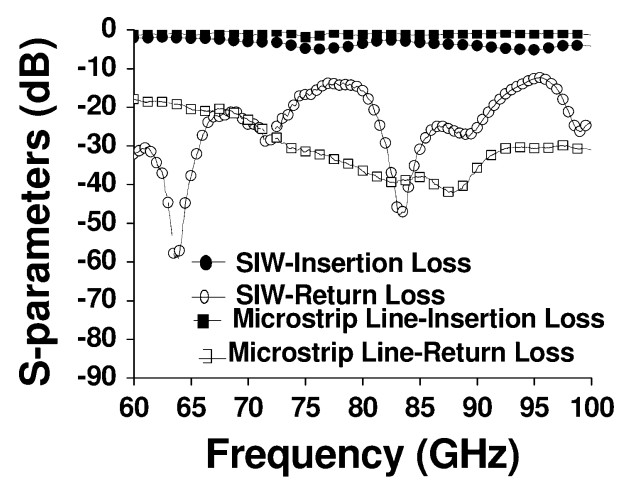

Fig. 15. $S$-parameters plotted for substrate integrated waveguide and a simple microstrip line.

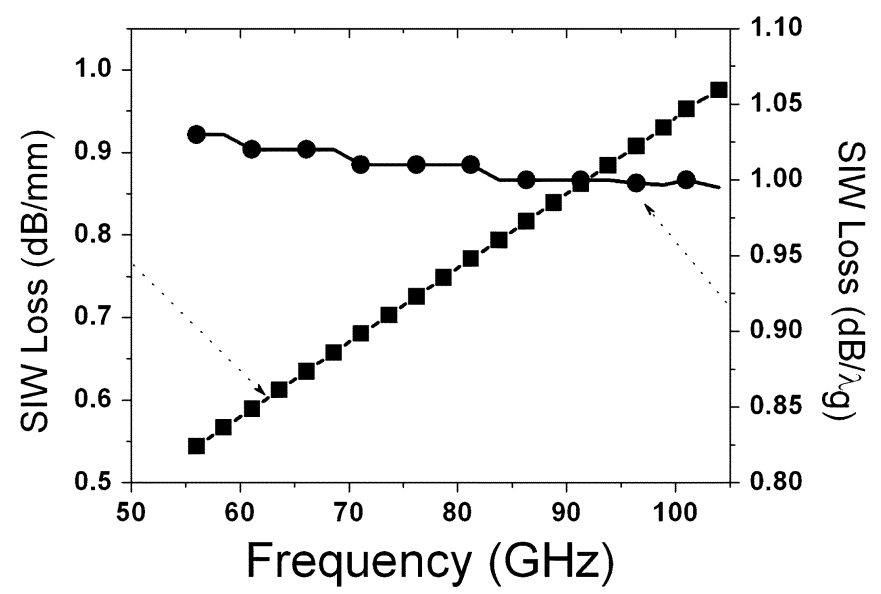

Fig. 16. Loss plotted in $\mathrm{dB} / \mathrm{mm}$ and $\mathrm{dB} / \mathrm{Ag}$ of a substrate-integrated waveguide of width $1.26 \mathrm{~mm}$.

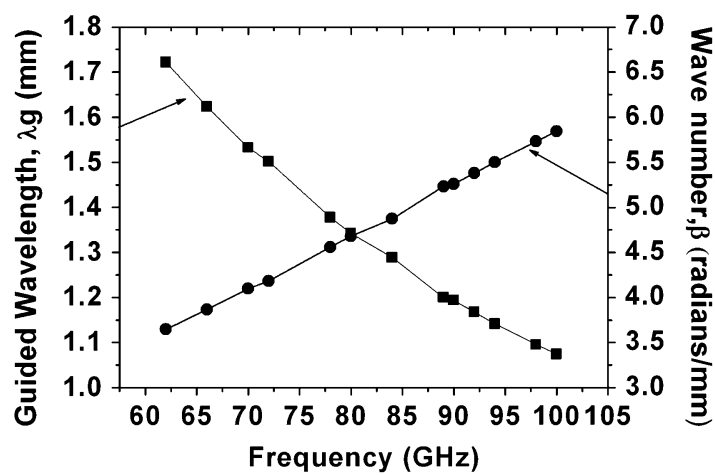

Fig. 17. The wave number $(\beta)$ and guided wavelength $\left(\lambda_{\mathrm{g}}\right)$ of a substrate integrated waveguide plotted against frequency.

wavelength deduced from the measured phase data. The loss was calculated to be $\sim 1 \mathrm{~dB} / \lambda_{\mathrm{g}}$ at $74 \mathrm{GHz}$. It can be seen that the losses are relatively small and this indicates that the integrated waveguide structure is a usable interconnection technology up to high millimeter-wave frequencies.

Similar loss measurements were carried out for folded waveguides and it was found that the losses increased by around $20 \%$. This relatively small increase in loss, compared with the simple unfolded structure, indicates that the folded waveguide concept is viable in practical situations where substrate area is at a premium. Fig. 18. shows images of the folded waveguide structures used for the insertion loss measurements.

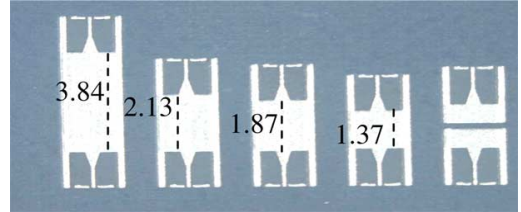

Fig. 18. Folded waveguide sections of different length for insertion loss measurement (dimensions in millimeters).

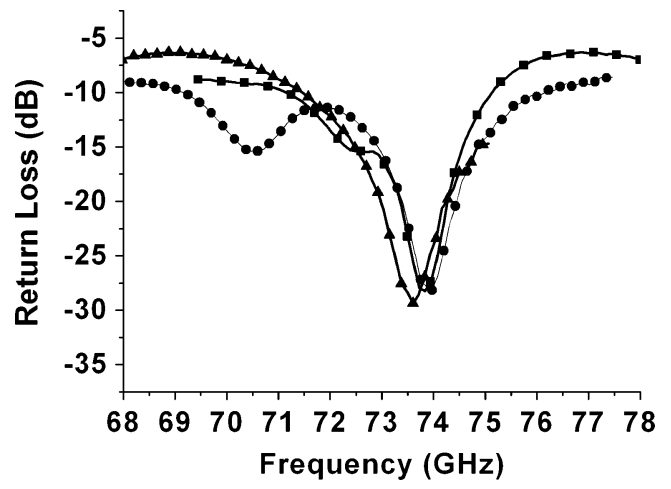

Fig. 19. The measured frequency response of three identical SIW antennas to illustrate the repeatability of thick-film processing.

TABLE II

THREe-Dimensional Tolerances Measured on the CRITICAL DimENSIONS OF SIW AND SIW ANTENNAS AFTER PROCESS MODIFICATION

\begin{tabular}{|l|c|c|c|c|c|}
\hline Geometry & $\begin{array}{l}\text { Length } \\
(\%)\end{array}$ & $\begin{array}{l}\text { Width } \\
(\%)\end{array}$ & $\begin{array}{l}\text { Height } \\
(\%)\end{array}$ & $\begin{array}{l}\text { Slot } \\
\text { length } \\
(\%)\end{array}$ & $\begin{array}{l}\text { Slot } \\
\text { width } \\
(\%)\end{array}$ \\
\hline SIW & 0.9 & 1.9 & 2 & - & - \\
\hline $\begin{array}{l}\text { SIW } \\
\text { Antenna }\end{array}$ & 1.1 & 2 & 2 & 0.6 & 4 \\
\hline
\end{tabular}

\section{REPEATABILITY AND TOLERANCE ANALYSIS OF THICK FILM PROCESS}

The section details the repeatability and tolerance involved in the thick film fabrication process. The frequency response of the substrate integrated waveguide antenna fabricated on three different supporting ceramic substrates is shown in Fig. 19. The plot shows almost similar results for the same structure, which has gone through different printing and firing process and illustrates the repeatability of the thick film process in constructing substrate integrated waveguide structures. Table II gives the 3-D tolerance measured on the critical SIW dimensions. The percentage values shown in the table are calculated by measuring the dimensions of the fabricated geometry after the process modifications to account for shrinkage. The results indicate that the geometrical dimensions could be achieved within 5\% under well-controlled process.

\section{Analysis of Integrated WaVEguide Performance}

The primary aim of the current study was to establish the potential of photoimageable thick-film technology for fabricating miniature mm-wave components. An antenna, using novel techniques, was chosen for the investigation because it was relatively demanding in terms of the required quality of fabrication and 
TABLE III

PERFormanCE COMPARISON TABLE FOR SIW AND A CONVENTIONAL Metallic Antenna ARRAY at $74 \mathrm{GHz}$

\begin{tabular}{|l|l|l|}
\hline Parameter & $\begin{array}{l}\text { SIW antenna array } \\
\text { (Measured) }\end{array}$ & $\begin{array}{l}\text { Metallic air- } \\
\text { filled waveguide } \\
\text { array } \\
\text { (Calculated) }\end{array}$ \\
\hline Gain & $3 \mathrm{~dB}$ & $3.958 \mathrm{~dB}$ \\
\hline $\begin{array}{l}\text { Loss in the } \\
\text { waveguide }\end{array}$ & $0.7 \mathrm{~dB} / \mathrm{mm}$ & $0.00402 \mathrm{~dB} / \mathrm{mm}$ \\
\hline Physical Area & $4.24775 \mathrm{~mm}^{2}$ & $28.95 \mathrm{~mm}^{2}$ \\
\hline
\end{tabular}

also because of the small dimensions that were needed. A further benefit of the choice of an antenna was that there was performance data available in the literature [16] for antennas fabricated using other technologies, against which the performance of the integrated substrate approach could be compared.

Obviously, it was important to obtain some indication of the efficiency of the SIW antenna in comparison with the more conventional microstrip patch array at mm-wave frequencies. For this efficiency analysis, the total loss (dielectric and conductor) for a section of waveguide is compared to that of an equivalent microstrip line. Direct comparisons are difficult, because microstrip interconnections normally have an impedance of $50 \Omega$, whereas waveguide has a somewhat higher impedance However, if we compare microstrip having the same overall dimensions as the integrated waveguide, i.e., occupying the same substrate area, then we find that the microstrip has a loss around $50 \%$ higher than that of the integrated waveguide. Moreover, for an array giving similar radiation performance the total area of the substrate integrated waveguide antenna will be $\sim 1 / 10$ th of that occupied by a microstrip [16]. Therefore, the substrate integrated waveguide structure will offer an advantage in terms of reduced surface area and efficiency that will be significant for highly integrated millimeter-wave circuits, where substrate area is at a premium.

The three-slot substrate integrated waveguide antenna performance has been compared with that from a conventional metallic air-filled waveguide antenna, as shown by the data in Table III. In this table, the gain for a conventional metallic wavguide antenna was calculated from [17] and the total loss is calculated from [18]. The minimum physical area was calculated for both antennas, and for the SIW the physical area was reduced by $\sim 85 \%$ compared to the metallic waveguide air-filled antennas.

\section{CONCLUSION}

The results have demonstrated that photoimageable thick-film technology is a viable approach for the fabrication of circuits working at high millimetre-wave frequencies, offering both low-loss interconnections and the potential to realise fine circuit geometries. The techniques of using the technology to fabricate 3-D integrated waveguides within a planar circuit proved successful, and led to the development of a high performance, miniature antenna working at $74 \mathrm{GHz}$. The technique could be extended to LTCC, which would permit parallel processing of the layers and avoid the need for the time consuming sequential processing of each layer.

\section{REFERENCES}

[1] W. Menzal and J. Kassner, "Millimeter-wave 3-D integration techniques using LTCC and related multi-layer circuits," in Proc. 30th Eur. Microwave Conf. Proc., Paris, France, 2000, pp. 33-53.

[2] D. Deslandes and K. Wu, "Design consideration and performance analysis of substrate integrated waveguide components," in Eur. Microw. Conf., Milan, Italy, Sep. 2002, pp. 881-884.

[3] Y. Cassivi, L. Perregrini, P. Arcoini, M. Bressan, K. Wu, and G. Conciauro, "Dispersion characteristics of substarte integrated rectangular waveguide," IEEE Microw. Wireless Compon. Lett., vol. 21, no. 9, pp. 333-335, Sep. 2002.

[4] W. R. McGrath, C. Walker, M. Yap, and Y.-C. Tai, "Silicon micromachined waveguides for millimeter-wave and submillimeter-wave frequencies," IEEE Microw. Guided Wave Lett., vol. 3, no. 3, pp. 61-63, Mar. 1993

[5] C. E. Collins et al., "A new micro-machined millimeter-wave and terahertz snap-together rectangular waveguide technology," IEEE Microw. Guided Wave Lett., vol. 9, no. 2, pp. 63-65, Feb. 1999.

[6] J. W. Digby et al., "Fabrication and characterization of micromachind rectangular waveguide components for use at millimeter-wave and terahertz frequencies," IEEE Trans. Microwave Theory Tech., vol. 48, no. 8, pp. 1293-1302, Aug. 2000.

[7] M. Henry, C. E. Free, B. S. Izquerido, J. Batchelor, and P. Young, "Photo-imageable thick-film circuits up to $100 \mathrm{GHz}$," in Proc. 39th Int Symp. Microelectron. IMAPS, San Diego, CA, Nov. 2006, pp. 230-236.

[8] D. Stephens, P. R. Young, and I. D. Robertson, "Millimeter-wave substrate integrated waveguides and filters in photoimageable thick-film technology," IEEE Trans. Microwave Theory Tech., vol. 53, no. 12, pp. 3822-3838, Dec. 2005.

[9] C. Y. Chang and W. C. Hsu, "Photonic bandgap dielectric waveguide filter," IEEE Microw. Wireless Compon. Lett., vol. 12, no. 4, pp. 137-139, Apr. 2002.

[10] Y. Cassivi, D. Deslandes, and K. Wu, "Substrate integrated waveguide directional couplers," presented at the Asia, Pacific Conf., Kyoto, Japan, Nov. 2002.

[11] D. Deslandes et al., "Integrated microstrip and rectangular waveguide in planar form," IEEE Microw. Wireless Compon. Lett., vol. 11, no. 2, pp. 68-70, Feb. 2001.

[12] K. Song, Y. Fan, and Y. Zhang, "Design of low-profile millimeterwave substrate integrated waveguide power divider/combiner,", Int. J. Infrared Millimeter Waves, vol. 28, no. 6, pp. 473-478, 2007.

[13] R. M. Knox, "Dielectric waveguide microwave integrated circuits-an overview," IEEE Trans. Microwave Theory Tech., vol. 24, no. 11, pp. 806-814, Nov. 1976.

[14] H. Jacobs, G. Novick, G. M. Locascio, and M. M. Chrepta, "Measurment of guide wavelength in rectangular dielectric waveguides," IEEE Trans. Microwave Theory Tech., vol. 24, no. 11, pp. 815-820, Nov. 1976.

[15] N. Grigoropoulos and P. R. Young, "Compact folded waveguide," in Proc. 34th Eur. Microwave Conf., Amsterdam, The Netherlands, 2004, pp. 973-976.

[16] F. Kolak and C. Eswarappa, "A low profile $77 \mathrm{GHz}$ three beam antenna for automotive radar," IEEE MTT-S Dig., vol. 2, pp. 1107-1110, 2001.

[17] C. A. Balanis, Antenna Theory Analysis and Design, 2nd ed. New York: Wiley.

[18] E. V. D. Glazier and H. R. L. Lamont, The Services Textbook of Radio. London, U.K.: Her Majesty's Stationery Office (HMSO), 1958, vol. 5, Transmission and Propagation.

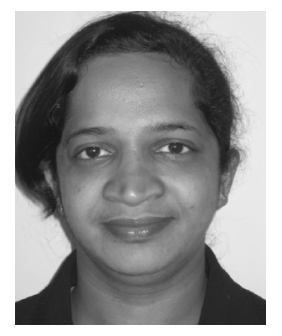

Manju Henry received the M.S. and Ph.D. degrees in electronic engineering from Cochin University of Science and Technology, Kerala, India in 1998 and 2002, respectively.

In 2002, she joined the Institute for High frequency and Microwave Techniques, Forshungszentrum, Karlsruhe, Germany as a Postdoctoral Researcher. From 2004 to 2006, she was a Research Fellow in the EPSRC funded project on millimeter wave antenna integration to ceramic multichip module technology at the University of Surrey, Guildford, U.K. She joined the MMT group at Rutherford Appleton Laboratory, Science and Technology Facilities Council, Chilton, U.K., in 2007, and is currently developing novel frequency selective surfaces and design topologies for Schottky-based frequency multipliers. She has more than 35 publications in international journals and conferences. 


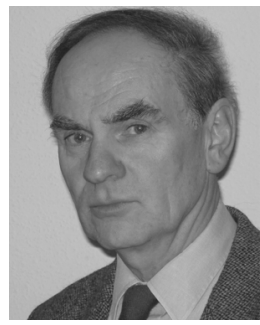

Charles Free is a graduate in electronic engineering. After working as a Senior Research Engineer in industry he moved to academia, and he is currently a Reader in Microwave Technology at the University of Surrey, Surrey, U.K. His research interests are primarily in microwave circuits and antennas. He is the author of over 100 papers.

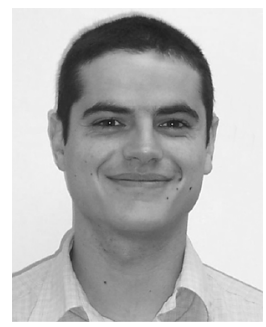

Benito Sanz-Izquierdo received the B.Sc. from the University of Las Palmas de Gran Canaria, Spain, in 1998 and the M.Sc. and Ph.D. degrees from the University of Kent, Kent, U.K., in 2002 and 2007, respectively.

He has been working as a Research Associate in the Department of Electronics of the University of Kent since 2003. His research interests are multiband, wearable antennas, RFID antennas, substrate integrated waveguides components, electromagnetic band-gap structures, and frequency selective

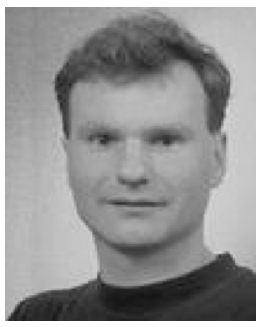

John C. Batchelor (SM'07) received the B.Sc. and $\mathrm{Ph} . \mathrm{D}$. degrees from the University of Kent, Canterbury, U.K., in 1991 and 1995, respectively.

From 1997 to 2006, he was a Lecturer with the Electronics Department, University of Kent, and in 2006, he became a Senior Lecturer of electronic engineering. His current research interests include printed antennas, body-worn antennas, electromagnetic- band gap structures, and low-frequency frequency-selective surfaces for application in smart buildings.

surfaces. 